\title{
Economic growth and environmental Kuznets curve for CEMAC zone countries: does deforestation matters?
}

\author{
"Yollande Tankeu Meli a*, Saubaber Longang Gamo a, Hilaire Nkengfack a, Ibrahim Ngouhouo a" \\ a tankeuyollande@gmail \\ "a Faculty of Economics and Management, University of Dschang, Cameroon"
}

\begin{abstract}
The aim of this paper is to analyze the relationship between economic growth and the rate of deforestation in the CEMAC zone countries, through an audit of the environmental Kuznets curve (EKC). We assess the contribution of the degree of trade openness in explaining Deforestation. Using the Generalized Least Squares method, on a panel of six (06) countries over the period 1996 - 2011, our study reveals that there is an EKC between the rate of deforestation and GDP per capita at a turning point of $\$ 7.9631$. Also, the results disclose that the degree of trade openness significantly increases the rate of deforestation by $0.5 \%$. Improving population standards of living will therefore reduce deforestation in CEMAC area.
\end{abstract}

Keywords: Economic Growth, Environmental Kuznets Curve, panel data, GLS, CEMAC

\section{Introduction}

The various conferences on the environment in Rio de Janeiro 1992, Johannesburg in 2002, Stockholm in 2009 and COP 21 in Paris last made climate change one of the major challenges of the millennium. Studies by the World Bank and the IPCC have shown that low-income countries are more vulnerable to climate change than rich countries, for two reasons. Firstly, their geographical location and also the sensitiveness of their economies to climate as highly dominated by agricultural activities. Climate statistics record an increase of $\mathrm{CO} 2$ emissions by $48 \%$ from 1900 to 2000 and $83 \%$ from 2000 to 2010 , and temperature rise from $2^{\circ} \mathrm{C}$ to $3{ }^{\circ} \mathrm{C}$ (UN 2013). This has many implications for the continent's whole economy and according to Mendelsohn (2009) who predicts that any further warming will seriously affect the productivity of the continent.

Although Africa is responsible for only $4 \%$ of global emissions of greenhouse gases, the continent is considered the most vulnerable to the impacts of climate change (IPCC, 2007). The vulnerability of the African economies to climate change has been recognized as substantial in key sectors such as agriculture, forestry, energy, tourism and water resources. Indeed, the geographical location of most African countries already in low latitude undermines the region in which $80 \%$ of the damage from climate change is concentrated. Any additional increase in temperature could hardly influence people's productivity (Mendelsohn, 2009). Currently, Africa contributes very little to emissions of greenhouse gas effects, less than $5 \%$ of the global emissions, and this share will grow significantly in the near future (Earth Trends, 2009).

Without exception, the countries of the CEMAC zone are known as developing countries. The need to find policies that can help transform their economies into emergent ones is real. However, the emergence of these countries requires an increase in the share of the industrial sector, which remains the major source of pollution and deforestation.

Hence, the most important forest pressures in the Congo Basin deforestation front do include development. To illustrate, Bennett (2017) identifies firewood, small scale agriculture and colonization as first and major causes, followed by secondary sources of deforestation which are large scale agriculture, unsustainable logging, mining and infrastructures. The last and the least important deforestation source is livestock. Trials to 
modernize economies and achieve high economic growth will provoke deforestation, producing negative externalities around the world.

The effects of deforestation are not located only where the cutting itself takes place. For instance, a $100 \%$ clearing of the Amazon deforestation would reduce rainfall in the US Midwest, Northwest and parts of the South during the agricultural season. Similarly, complete deforestation of Central Africa would likely cause declines in precipitations in the Gulf of Mexico and parts of the US Midwest and Northwest, and increase it on the Arabian Peninsula. Precipitation could also decline in Ukraine and southern Europe (Lawrence and Vandecar, 2014).

Understanding the relationship between macroeconomic variables and deforestation in CEMAC countries is the main focus of this study, which boils down to Test the relationship between economic growth and the rate of deforestation in the countries of the CEMAC zone precisely Cameroon, Gabon, Equatorial Guinea, Central African Republic, Congo, and Chad.

\section{Literature review}

\subsection{Theoretical literature}

The environmental Kuznets curve postulates the existence of an inverted-U relationship between per capita income and environmental degradation. Depending on the scenario, environmental degradation increases in poor countries and gradually decreases as countries become richer.

To clarify the relationship between these two variables, the study of Grossman and Krueger (1991) on the environmental impact identified three effects that occur following trade liberalization: the scale effect, the composition effect and the technical effect.

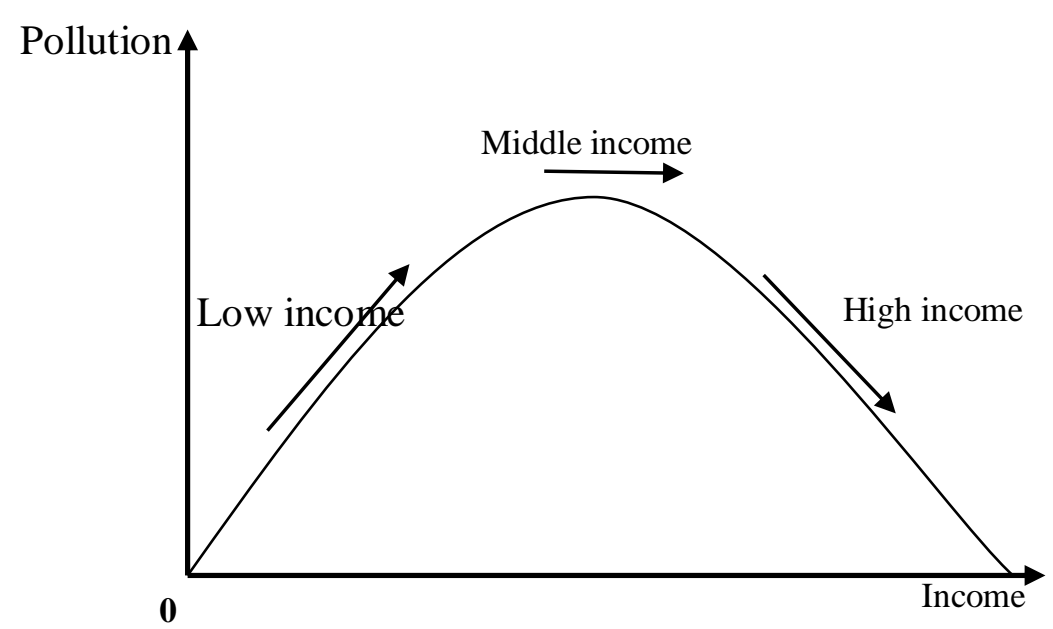

Figure 1:Environmental Kuznets Curve 
The scale effect captures the relationship between the increase of trade and the expansion of economic activity. It handles the increase of pollution with the size of economic activities involving that any increase in the level of economic activity (not as a result of the transformation of economic structures), will raise up pollution and environmental quality.

The composition effect refers t the change and transformation of the economic structure induced by the international specialization of countries participating to the trade. It is based on the Heckscher-Ohlin conventional approach according to which trade liberalization stimulates countries to specialize in activities where they have a comparative advantage.

The technical effect is the medium by which trade liberalization influences industries and households degree of pollution. Production techniques improvements reduces greenhouses emissions and other type of pollution.

\subsection{Empirical literature}

The first studies on the empirical verification of the EKC are those of Grossman and Krueger (1991) on Environmental impacts of North American Free Trade Agreement, Shafik and Bandyopadhyay (1992) in the World Bank Development report, and Panayotou (1993) for the International Labor Organization.

Akpan and Chuku (2011) undertake study in Nigeria on the relationship between the CO2 emissions, economic growth and electricity consumption over the period 1960-2008. Using in non-cubic model, they get an inverted-N Curve adjusting the emissions of CO2 and GDP per capita relationship. This result suggests that the positive effects of economic growth on the environment are temporary. In the same study, they analyze the effects of trade liberalization on the quality of the environment in Nigeria and conclude that any increase in trade openness ratio has a positive and significant impact on $\mathrm{CO} 2$ emissions.

Contrarily to the previous authors, Usenobong et al. (2012) examine the relationship between economic growth and the environmental degradation in Nigeria and find an $\mathrm{N}$ curve. They recommend that environmental preservation policies and measures should be adopted irrespective to the country's level of income.

Zwan (2007) examines the relation between income and land clearing for households living in tropical forest regions. He builds a simple model of the agricultural household that clears land for agriculture to investigate the link between lagged income and cleared land holdings. The study uses panel data from Peru and suggests that lagged income is positively correlated with clearing, though at a decreasing rate, and, because of labor market restrictions, clearing is positively associated with household labor availability. Equally the work suggests that small increases in the incomes of the poorest are unlikely to reduce deforestation in this context.

Arouri et al. (2012) have also examine the link between Economic Growth and CO2 Emissions of 12 North Africa countries between 1981 and 2005. Using Different panel methods, they conclude that the Real GDP present a quadratic relationship with the $\mathrm{CO} 2$ emissions for the entire region. The results support the existence of EKC for several countries studied. However, they noted that the turning points are low in some countries and very high in others. They therefore conclude that not all countries in the region need to sacrifice economic growth to reduce the level of $\mathrm{CO} 2$ emissions since they can reduce through energy conservation without experiencing the negative long-term effect on growth.

Olarinde et al. (2014) analyzed the relationship between economic growth and CO2 emissions in West Africa over the period 1970-2011. Using a panel model, authors conclude that there is a long-term equilibrium relationship between $\mathrm{CO} 2$ emissions, economic growth, macroeconomic policies, population size and trade openness. The major finding of their study is that the hypothesis of the existence of a EKC is not verified for West Africa. However, they found an $\mathrm{N}$ relationship, implying that pollution will tend to increase when the 
country is at it is early development stage, and then will decline once the GDP will be at its threshold, and finally will expand with national income increases.

Cuaresma and Heger (2019) examine economic development and deforestation linkages using tree cover loss data for 14 countries. The researchers use geographical regression discontinuity (using national borders as discontinuities) and find that Sub-Saharan Africa and low-income countries in general have the highest development-deforestation elasticity.

Andrée et al, 2020 estimated a penalized non-parametric model of environmental output across economic development. A kind of modeling which suits well with nonlinear processes that do not result in overly complex dynamics. To deal with heteroskedastic variance, the authors transformed data to logarithmic degradation intensity of per capita GDP. They then used a cross-validation approach to decide which fixed effects should be part of the model and this did not support the inclusion of time fixed effects. They find that production gradually encourages conserving the earth's finite resources as GDP rises, but that this alone is not sufficient to offset the scale effect of growth. Instead, structural change in the economy shapes environmental output curves. They conclude that those results do not support a single environmental Kuznets rule, but they emphasize the importance of local economic conditions on environmental results. They claim that deforestation follows an inverted U-shape across average development in the developing countries.

Miyamoto (2020) conducts a research on poverty reduction and forests sustainability. In that study, he examines the main factors influencing forest area change by synthesizing the results of a multinational data analysis, a Malaysian socio-economic survey, and Indonesian household surveys on deforestation that were conducted between 1990 and 2014. The author reveals that poverty has a strong impact on forest area change and that high agricultural rent accelerates deforestation. He then suggests that poverty-alleviation strategies can represent crucial and effective methods for reducing rainforest destruction.

Santiago and Couto (2020) carry on a study on socio-economic development versus deforestation. In their study, they evaluated the relationship between the deforestation and the socioeconomic development in Brazil, from 2000 to 2010. They fitted a multiple linear model of fixed effects to the data that composed a balanced panel with 3168 observations. Their findings suggest that the Brazilian socioeconomic development is intensively linked to the use of forest resources, leading to two problems: the ephemeral improvement in development as shown by the indicators; and the favoring of income concentration.

\section{Methodology}

\subsection{Nature and source of data}

The data used in this research are from secondary sources of six (06) countries from the CEMAC zone over the period 1996-2011. This period is of crucial importance. Indeed, it was during this period that the CEMAC countries were all beneficiaries of the Heavily Indebted Poor Countries (HIPC) initiative and committed to reaching the completion point. To relate growth rate of GDP per capita and to Deforestation rate, we variables extracted from the World Bank indicators database (WDI), except quality of regulation (QR) which comes from the Worldwide Governance Indicators (WGI).

\subsection{The Baseline model}

For the general reader, suffice is to say that our baseline model is given by the following Kuznets equation:

$$
Y_{i t}=\beta_{0}+\beta_{j} X_{j i t}+\beta_{k} Z_{k i t}+e_{i}+v_{t}+\mu_{i t}
$$


Where $Y_{\text {it }}$ is the environmental variable (Deforestation), $\mathrm{X}$ is the set of our $\mathrm{j}$-interest variables (Incomes) and $\mathrm{Z}$ is the set of $\mathrm{k}$-control variables which can influence deforestation. ${ }_{i}{ }_{i}$ is the error term constant over time, depending only on the individual $\mathrm{I},{ }^{v_{t}}$ is the error term depending only on time and $\mu_{i t}$ representing the random cross term.

The complete model can be fully written as:

$D E F_{\text {it }}=\beta_{0}+\beta_{1} G D P_{\text {it }}+\beta_{2} G D P_{\text {it }}^{2}+\beta_{2} O U V_{\text {it }}+\beta_{4} A V I_{\text {it }}+\beta_{5} D E N_{\text {it }}+\beta_{6} A V A_{\text {it }}+$ $\beta_{7} C S P_{i t}+\beta_{8} Q R_{i t}+\mu_{i}+v_{t}+w_{i t}$

\subsection{The variables}

Table 1 below displays variable names, the expected signs, the supporting references and their respective sources likewise.

Table 1: Variables and expected signs

\begin{tabular}{llcll}
\hline Variable & \multicolumn{1}{c}{ Description } & $\begin{array}{c}\text { Expected } \\
\text { signs }\end{array}$ & Supporting References & Source \\
\hline DEF & Deforestation rate & $/ /$ & - & WDI \\
GDP & per capita income & + & Zwane (2007), Santiago and Couto (2020) & WDI \\
GDP & per capita income square & - & Wang et al. (2016), Santiago and Couto (2020) & WDI \\
TOD & Trade openess degree & + & Eskandar (2013) & WDI \\
AVA & Agricultural value added & + & Miyamoto (2020), Santiago and Couto (2020) & WDI \\
& share & & & André et al, (2019); Santiago and Couto (2020) \\
IVA & Industrial value added share & + & WDI \\
DEN & Population density & + & André et al, 2019; Santiago and Couto (2020) & WDI \\
CSP & Credit to the private sector & + & Olarinde (2014) & WDI \\
QR & Quality of reglementation & - & - & WGI \\
\hline
\end{tabular}

The functional form of the model is quadratic, based on the relationship between endogenous (DEF) and exogenous variable, referring to economic growth (GDP). The fact we expect a quadratic form is due to the hypothesis of the Environmental Kuznets Curve (Wang et al., 2016; Apergis et al., 2017).

\subsection{Estimation strategy}

After establishing the baseline model and the functional form, we analyse our panel data. Four regression models were tested: pooled regression, fixed effects, random effects and feasible general least square (Gujarati, 2000). Coefficient estimation is by Ordinary Least Square (OLS) method for the pooled regression and fixed effects and by General Least Square (GLS) method for the random effects and the feasible general least square alike. In the fixed effects model, the assumption is that the intercept varies between the countries and remains constant between years. Meanwhile for the random effects model, the intercept varies for both countries and years (Wooldridge, 2014).

To determine which of the fixed effects and the random effects is more appropriate we use the Hausman test (Hausman, 1978). According to the later, under null hypothesis the random effects estimators are the most adequate to estimate the regression coefficient. We rejected the alternative hypothesis and the random effects estimators appeared more suitable to interpret. The estimators derived from other techniques are used to check robustness of parameters. 


\section{Results}

\subsection{Results of unit root tests (stationary tests)}

To verify the stationary of the series we use Im Pesaran Shin (IPS) unit root tests (Baltagi, 2005) which is a first generation unit root test. The results are reported in Appendix, Table 1.

The result from the IPS tests discloses that our endogenous variable Deforestation (DEF) is stationary at level, as well as quality of regulation (QR), trade openness degree (TOD), agricultural value added (AVA) and industrial sector value added (IVA). The test reveals the set of variables gross domestic product and gross domestic product squared, population density (DEN) and credit granted to the private sector (CPS), is integrated of order one.

\subsection{Descriptive statistics of variables}

From Table 2 it is shown that in the panel, the tree cover depletion is around 3,7\% average each year. That mean is very close to the maximum rate of deforestation over the considered period. This means the rate of deforestation is very high in general, and does not change too much as the standard deviation is only 0,72 . The average living standards in countries is $\$ 7,63$ an the countries have rather similar living standards in the region. This is comforted by the fact that the overall panel standard deviation is $\$ 1,22$. The highest income per head is up to $\$ 9,622$ and the lowest income value is $\$ 5,644$ and which stresses the persistence of poverty in countries but several income disparities among population.

Table 2: Descriptive statistics

\begin{tabular}{lrrrrr}
\hline Var & obs & \multicolumn{1}{c}{ mean } & Std. dev. & \multicolumn{1}{l}{ Min } & \multicolumn{1}{c}{ Max } \\
\hline DEF & 102 & 3,732 & 0,719 & 2,2 & 4,44 \\
GDP & 108 & 7,364 & 1,223 & 5,644 & 9,622 \\
GDP2 & 108 & 55,709 & 18,634 & 31,854 & 92,59 \\
DEN & 108 & 14,912 & 12,028 & 4,302 & 47,077 \\
CSP & 108 & 7,115 & 3,376 & 2,097 & 14,93 \\
QR & 108 & $-0,985$ & 0,399 & $-1,715$ & 0,141 \\
AVA & 88 & 2,391 & 0,47 & 1,521 & 3,248 \\
IVA & 88 & 3,389 & 0,688 & 2,242 & 4,439 \\
TOD & 101 & 4,466 & 0,67 & 3,433 & 6,276 \\
\hline
\end{tabular}

The average density is relatively high with an average of 14,91 and a maximum of 47,07 and a minimum of only 4,302. Then, density is greatly variable among countries and over time with and has a standard deviation of 12,02 habitants per kilometer squared. With an average of 2,391 agricultural value added has a lower contribution than the industrial value added which supports overall GDP with 3,389 in average. That is to say industrial sector is of greater importance to economic growth and for environmental threats. The cemac zone countries do have almost the same open trade ratio in average, considering the overall means and standard deviation of 4,46 and 0,67 respectively. 


\subsection{Estimation results and performances}

The long-term coefficients of the impact of growth on environmental quality were estimated following 4 specifications are: ordinary least squares, fixed effects model, random effects and the feasible general least squares and the results are shown in table 2.

Table 3: Verification of the Kuznets curve for deforestation

\begin{tabular}{|c|c|c|c|c|}
\hline \multirow[b]{2}{*}{ Dependent variable : DEF } & \multicolumn{4}{|c|}{ Estimation Techniques } \\
\hline & OLS & FE & $\mathrm{RE}$ & FGLS \\
\hline GDP & $\begin{array}{l}0,3407 * * * \\
(0,0811)\end{array}$ & $\begin{array}{l}.4527 * * * \\
(.0443)\end{array}$ & $\begin{array}{l}.4544 * * * \\
(.0319)\end{array}$ & $\begin{array}{l}.03407 * * * \\
(.0763)\end{array}$ \\
\hline GDP $^{2}$ & $\begin{array}{l}-0,0855 * * \\
(0,0439)\end{array}$ & $\begin{array}{l}.0182 * * * \\
(.0017)\end{array}$ & $\begin{array}{l}-.01681 * * * \\
(0,0141)\end{array}$ & $\begin{array}{l}-0,0855^{* *} \\
(.04134)\end{array}$ \\
\hline AVI & $\begin{array}{l}0,6384 * * * \\
(0,2339)\end{array}$ & $\begin{array}{l}-.2283^{* *} \\
(.1114)\end{array}$ & $\begin{array}{l}-.18886 * * \\
(.0857)\end{array}$ & $\begin{array}{l}0,6384 * * * \\
(.2201)\end{array}$ \\
\hline AVA & $\begin{array}{l}0,0103 \\
(0,0076)\end{array}$ & $\begin{array}{l}-.02122 * * * \\
(.0039)\end{array}$ & $\begin{array}{l}-.02048 * * * \\
(.00307)\end{array}$ & $\begin{array}{l}0,0103 \\
(.0072)\end{array}$ \\
\hline TOD & $\begin{array}{l}0,6227 * * * \\
(0,0604)\end{array}$ & $\begin{array}{l}.5205^{* * * *} \\
(.0375)\end{array}$ & $\begin{array}{l}.5051 * * * \\
(.02582)\end{array}$ & $\begin{array}{l}0,6227 * * * \\
(.0568)\end{array}$ \\
\hline QR & $\begin{array}{l}0,2165^{*} \\
(0,1146)\end{array}$ & $\begin{array}{l}-.28385 * * * \\
(.0826)\end{array}$ & $\begin{array}{l}-.29505 * * * \\
(.04908)\end{array}$ & $\begin{array}{l}0,2165^{*} \\
(.1079)\end{array}$ \\
\hline CPS & $\begin{array}{l}0,0311 * * * \\
(0,0114)\end{array}$ & $\begin{array}{l}.00455 \\
(.0070)\end{array}$ & $\begin{array}{l}-.0001 \\
(.00573)\end{array}$ & $\begin{array}{l}0,0311 * * * \\
(.0108)\end{array}$ \\
\hline DEN & $\begin{array}{l}0,6269 * * * \\
(.00193)\end{array}$ & $\begin{array}{l}-.02876 * * * \\
(.00229)\end{array}$ & $\begin{array}{l}-.0290 * * * \\
(.0020)\end{array}$ & $\begin{array}{l}0,6269 * * * \\
(.00193)\end{array}$ \\
\hline Cons & $\begin{array}{l}-4,1975 * * * \\
(0,9633)\end{array}$ & $\begin{array}{l}-1.242 * * \\
(.5594)\end{array}$ & $\begin{array}{l}-1.3192 * * * \\
(.4000)\end{array}$ & $\begin{array}{l}-4,1975^{* * * *} \\
(.9067)\end{array}$ \\
\hline $\mathbf{R}^{2}$ & 0,9337 & & & \\
\hline Adjusted R $\mathbf{R}^{2}$ & 0,9261 & & & \\
\hline $\mathbf{R}^{2}$ intra & & 0.9943 & 0,9941 & \\
\hline $\mathbf{R}^{2}$ Between & & 0.5018 & 0,5385 & \\
\hline $\mathbf{R}^{2}$ global & & 0.9915 & 0,9918 & \\
\hline Observations & 70 & 67 & 67 & 79 \\
\hline Stats & 123,13 & 910.95 & 7015.26 & 8104.13 \\
\hline Prob & 0.0000 & 0,0000 & 0,0000 & 0.0000 \\
\hline Hausman & & 18.43 & & \\
\hline Prob & & 0.2612 & & \\
\hline
\end{tabular}

$\mathrm{NB}: *, * *, * * *$ represents the significance at the $10 \%, 5 \%$ and $1 \%$ significance level respectively Sources: Authors estimates from Stata 13

Per capita income (GDP)

From our estimations, economic growth has a positive and significant effect on deforestation in CEMAC at the $1 \%$ threshold. An increase of GDP by 1 point will lead to an increase in deforestation of 0.45 percentage 
point for the RE estimator and 0.03 percentage point for the GLS estimator. The result is in line with our expectations and suggests that deforestation is positively related to economic activity. This may be explained by the fact that economic development requires the use of forests to move from an underdeveloped economy to a service economy. The result is robust as the sign of estimated parameter with OLS and FE remain the positive.

Per capita income squared (GDP2).

The per capita income (GDP2) has a negative and significant effect on deforestation at the 5\% threshold; a 1 point increase in GDP2 will result in a 0.017 percentage point decrease of deforestation according to the RE estimators. This sign is in line with our forecasts and suggests that in the long run, the rate of deforestation will decrease with economic growth from a certain threshold. The obtained result is robust since the FGLS and the OLS displays a significant fall in deforestation rate of 0,09 . The finding corroborates those of HoltzEakin and Selden (1995) Cissoko, (2004); Santiago and Couto, (2020) and may find an explanation in the structure of the economy.

In actual fact, the economies of the CEMAC zone are still in their embryonic stages of development and depend on their natural resources. The result shows that economic development comes along with environmental deterioration including rainforest destruction. Fortunately, civil society activism, environmentalist defenders campaign for environmental protection, which will help bring down the cutting trees rate due to economic growth.

Also, good environmental and institutional management could help relocate polluting companies. In addition, investments in research and development or the import of clean technologies could be beneficial for these CEMAC member states.

\section{Industrial GDP (IVA)}

Our estimates show that industrial production has a positive and significant effect on deforestation at the $1 \%$ threshold. Indeed, an increase in industrial value added by one unit will result in an increase of deforestation by 0.64 percentage points. This seems normal since these countries aspire to emerge and undertake major structuring projects that are a major source of pollution. This result is deals with our forecasts and can be justified by the fact that the economies of the CEMAC countries are driven by an obsolescent polluting industrial sector. In fact the desuetude of industrial units on the one hand increases greenhouses emissions and acid rains which destroy forests (Mohajan, 2019). On the other hand, industrial waste issued are captured by trees roots which unable them to grow properly. According to the RE and FE estimators the result is not robust since it will rather lead to slowdown of the cutting tree by 0,19 and 0,23 percentage point respectively.

\section{Agricultural GDP (AVA)}

From our table, the agricultural value added has an ambiguous deforestation effect. The FE and RE estimators show that agricultural GDP increase will significantly dampen deforestation rate by 0.02 percentage point. However the GLS estimator finds that and increase in agricultural value added will increase cover tree depletion but this will not be significant. The result is different from Andrée et al, (2020) which shows that agricultural GDP correlates with deforestation. The theoretical explanation we give here is based 
on the direct relation between productivity and product. With the important rural exodus that CEMAC countries experience, many producers will abandon their farm activity. The productivity will then increase and the overall input as well, everything being equal.

The degree of trade openness (TOD)

Trade openness has a positive and significant effect on deforestation at the $1 \%$ level. Indeed, a $1 \%$ increase in the opening rate will lead to a 0.5 percentage point increase in deforestation rate if we consider the RE estimator. The effect is robust to other estimation techniques like GLS with a score of 0.62 , and FE for a score of 0.52 . This result corroborates the economic theory that assumes a positive relationship between trade openness and the environmental quality indicator that is deforestation here. One possible explanation can be found in the technical and scale effects that show how trade liberalization influences the degree of industrial and household.

The quality of regulations $(\mathrm{QR})$

From the model estimates, the quality of regulation significantly increases deforestation at the level of $1 \%$. This sign is at least intriguing and contrary to our predictions. It reveals that good quality regulation in CEMAC countries will cause accelerate environmental degradation and therefore deforestation. Indeed, the institutional effort of government observable through the various programs and actions is a rather dissuasive factor for agents. But this can find an unfavorable echo in their mind if they do not have a good environmental education, if they are too poor and/or if they rely on agricultural rents (Miyamoto, 2020).

The effect of quality of regulation is not robust. According to FE and RE quality of regulation improvement will help slowing deforestation activity. That is to say the effect of regulation on cover tree depends on the regulation itself. If the regulation is inclusive and understandable it may lead to reduce deforestation. Conversely, a hard to apply or not inclusive rule may accelerate deforestation rate.

\section{Population density (DEN)}

The population-related variable is significant showing that population density has a high positive effect on tree cover reduction at the $1 \%$ threshold. Thus, an increase in the population density of 1 point will drive up deforestation by a 0.02 percentage point. This result is in line with our expectations that there was a positive relationship between population density and deforestation. A justification of this result can be found in the fact that ambient poverty pushes rural populations to turn to forests to support their basic needs such as nutrition, heating and firewood trade. It is important to underline that population density environmental effects are not robust. They vary as the estimation technique changes. For instance, the FE and RE show that the population will reduce the rate of deforestation. This finding correlates with Andrée et al. (2020).

\section{Credit to the private sector (CPS)}

The share of credit to the private sector is positively and significantly related to the deforestation of tropical forests at the $1 \%$ threshold. Therefore, a high level of credit to the private sector implies a high level of deforestation. In other words, a high level of production from the private sector will have a significant negative impact on environmental deterioration including deforestation. The result is not robust since the RE estimator find negative and it not significant. 
In summary, it follows from this specification that the Kuznets environmental curve is verified because the coefficients of GDP and GDP2 are positive and negative, respectively, and all significant. It can be concluded that when environmental damage is captured by deforestation, there is an inverted U-curve for CEMAC zone countries with a breakpoint of $\$ 7.9631$.

\section{Conclusion and Policies implication}

\subsection{Conclusion}

In this paper we assessed the EKC hypothesis between per capita income and deforestation in six countries of the CEMAC zone over 1996-2011.

Applying diversified panel estimation techniques to the the EKC equation, we find that economic growth has a positive and significant effect on environmental indicator in the CEMAC zone. The effect of per capita GDP on the quality of the environment was highlighted by the application of generalized least square method. Whenever the environmental indicator is the rate of deforestation, we get an inverted-U in the country of the sample. The result is robust to the other estimation techniques. Our hypothesis is confirmed and admits the existence of EKC between growth and deforestation, with a breaking point of $\$ 7.9631$. This result is consistent with that of Bhattarai and Hammig (2002). Developing countries with tropical forests and average income below $\$ 7$ will continue to lose their forests. When incomes are above this level, conservation efforts will become effective and deforestation curve will be reversed.

\subsection{Policies implication}

For countries in the sample, the breaking point is located above the level of current income. This suggests that the growth of income alone cannot explain the process of deforestation in the area. So, a few recommendations can be made. Firstly, Governments should promote environmental education and poverty alleviation strategies, especially in rural areas. To add, Governments should promote inclusive and sustainable economic growth to allow a subsequent increase of equitable income redistribution. Thirdly, she should restructure and require private investors to increase their use of clean technologies and detracts from its impact on environmental degradation.

\section{References}

Akpan \& Chuku. (2011). Economic Growth and Environmental Degradation in Nigeria: Beyond the Environmental Kuznets Curve. MPRA, 27 April, p. 10-20

Andrée, B. P. J., Chamorro, A., Spencer, P., Koomen, E., \& Dogo, H. (2019). Revisiting the relation between economic growth and the environment; a global assessment of deforestation, pollution and carbon emission. Renewable and Sustainable Energy Reviews, 114,

Arouri, Mr. E. H, Youssef, A. B., M'henni, H., and Rault, C. (2012). Energy Consumption, Economic Growth and $\mathrm{CO} 2$ Emissions in Middle East and North African Countries.Discussion Paper Series, IZA DP No. 6412.

Baltagi, B. Econometric Analysis of Panel Data, 3rd ed. New York: John Wiley and Sons, 2005.

Bennett, L. (2017) Deforestation and Climate Change, The Climate Institute

Bhattarai, M; Hammig, M (2002): Governance, economic policy and the environmental Kuznets curve for natural tropical forests 
Cissoko, L. (2004). Impact of economic growth on the quality of the environment: the case of Senegal. Master of Arts Thesis (D.E.A) F.A.S.E.G, University of Cheikh AntaDiop Dakar, Senegal

Cuaresma, J. C., \& Heger, M. (2019). Deforestation and economic development: Evidence from national borders. Land Use Policy. doi:10.1016/j.landusepol.2018.12.039

Earth Trends (2009) The Environmental Information Portal, World Resources Institute, http://earthtrends.wri.org/text/water-resources/country-profile-179.html (accessed 14 January 2009).

Grossman, G \& Krueger, A. (1991). Environmental Impacts of a North American Free Trade Agreement. Quarterly Journal of Economics

Gujarati, D.N., 2000. Econometria Básica. São Paulo. MAKRON Books do Brasil Editora Ltda, 3a edição.

Hausman, J.A., 1978. Specification tests in econometrics. Econometrica 46 (6), $1251-1271$.

Holtz-Eakin, D and Selden T.M.(1995) Stocking the fires? CO2 emissions and economic growth. Journal of Public Economics, 57, 85-101

Lawrence, D., Vandecar, K. Effects of tropical deforestation on climate and agriculture. Nature Clim Change 5, 27-36 (2015). https://doi.org/10.1038/nclimate2430

Miyamoto, M. (2020). Poverty reduction saves forests sustainably: Lessons for deforestation policies. World Development, 127, 104746.

Mohajan, H. (2019). Acid Rain is a Local Environment Pollution but Global Concern. 3. 47-55.

Muftau, Olarinde \& Iyoboyi, Martins \& Sikiru Ademola, Abdulsalam. (2014). An Empirical Analysis of the Relationship between CO 2 Emission and Economic Growth in West Africa. 2014. 1-17. 10.5923/j.economics.20140401.01.

Panayotou, T.(1993). Empirical Tests and Policy Analysis of Environmental Degradation at Different Stages of Economic Development. Geneva International labor office, Technology and Employment program

Santiago A. R., and Couto do H. T. Z. (2020), Socioeconomic development versus deforestation: considerations on the sustainability of economic and social growth in most Brazilian municipalities, Environmental Development, https://doi.org/10.1016/j.envdev.2020.100520

Shafik, N. and Bandyopadhyay, S.1992. Economic growth and environmental quality : time series and crosscountry evidence (English). Policy, research working papers ; no. WPS 904. World development report. Washington, D.C. : World Bank Group. http://documents.worldbank.org/curated/en/833431468739515725/Economic-growth-and-environmentalquality-time-series-and-cross-country-evidence

United Nations. 2013 Annual report, United Nation Environment Program.

Usenobong, and E. A. Chukwu, A.C. (2012). Economic Growth and Environmental Degradation in Nigeria: Beyond the Environmental Kuznets Curve. American Journal of Economics. Vol.4, pp. 1-17

Wooldridge, J.M., 2014. Introdução à econometria: uma abordagem moderna, 4a edição. São Paulo: Cengage Learning.

Zwane, A.P., 2007. Does poverty constrain deforestation? Econometric evidence from Peru. J. Dev. Econ. 84 (1), 330 -349. https://doi.org/10.1016/j.jdeveco.2005.11.007. 


\section{Appendix A. Countries involved in the study}

Cameroon, Chad, Central African Republic, Equatorial Guinea, Gabon, Republic of the Congo

Appendix B. Results of the stationarity tests

\begin{tabular}{llllll}
\hline \multirow{2}{*}{ Variables } & At level & \multicolumn{3}{l}{ In differences } & \multirow{2}{*}{ Decision } \\
\cline { 2 - 5 } & stats & Prob & Stats & Prob & \\
\hline DEF & $-2,76 * * *$ & 0,003 & - & - & $\mathrm{I}(0)$ \\
GDP & $-0,6503$ & 0,257 & $-2,4902 * * *$ & 0,006 & $\mathrm{I}(1)$ \\
GDP $^{2}$ & $-0,4918$ & 0,3114 & $-2,4741 * * *$ & 0,007 & $\mathrm{I}(1)$ \\
DEN & 1,1811 & 0,987 & $-5,210 * * *$ & 0,000 & $\mathrm{I}(1)$ \\
CPS & $-0,8200$ & 0,2061 & $-3,573 * * *$ & 0,002 & $\mathrm{I}(1)$ \\
QR & $-1,9208 * *$ & 0,027 & - & - & $\mathrm{I}(0)$ \\
TOD & $-2,5402 * * *$ & 0,0055 & - & - & $\mathrm{I}(0)$ \\
AVA & $-2,9978 * * *$ & 0,0014 & - & - & $\mathrm{I}(0)$ \\
IVA & $-2,6985 * * *$ & 0,0035 & - & - & $\mathrm{I}(0)$ \\
\hline
\end{tabular}

NB: *,**,***10\%,5\% and $1 \%$ represent the signification points respectively. 